\title{
AS POLIITICAS PÚBLICAS EDUCACIONAIS DA DITADURA EMPRESARIAL-MILITAR BRASILEIRA NO BOJO DAS DISPUTAS ENTRE FRAÇÕES BURGUESAS PELOS RUMOS DA EDUCAÇÃO'1
}

Renata Azevedo Campos ${ }^{2}$

\begin{abstract}
Resumo
O artigo tem por finalidade a análise da política educacional da ditadura empresarial-militar brasileira tendo em vista as demandas do então modelo de desenvolvimento para a educação. Sabendo que a burguesia não se constitui de modo homogêneo, as políticas foram pensadas à luz de dois projetos educacionais, correspondentes a duas frações da burguesia brasileira: da burguesia multinacional e associada, organizada no Instituto de Pesquisa e Estudos Sociais e dos empresários de ensino, participantes dos Congressos Nacionais dos Estabelecimentos Particulares de Ensino.
\end{abstract}

Palavras-chave: Política educacional; IPES; CONEPE.

\begin{abstract}
The article aims to analyze the educational policy of the Brazilian corporatemilitary dictatorship in view of the demands from the development model for education. Knowing that the bourgeoisie does not constitute homogeneously, the policies were considered in the light of two educational projects, corresponding to two fractions of the Brazilian bourgeoisie: the multinational and associated bourgeoisie, organized at the Instituto de Pesquisa e Estudos Sociais and educational entrepreneurs, participants of the Congressos Nacionais dos Estabelecimentos Particulares de Ensino.
\end{abstract}

Keywords: Educational policy; IPES; CONEPE.

\footnotetext{
${ }^{1}$ DOI: https://doi.org/10.22409/tn.15i28.p9641

${ }^{2}$ Doutoranda em Educação na Universidade Federal Fluminense, mestre em Educação pela UFF e graduada em História pela UFF. Atua como professora da disciplina História na Rede Municipal de Belford Roxo. Email: renataazevedort@gmail.com

TrabalhoNecessario - www.uff.br/trabalhonecessario; Ano 15, №28/2017
} 


\section{Introdução}

A educação brasileira encontrava-se, quando do golpe empresarial-militar de 1964, relativamente defasada em vista da complexificação das relações capitalistas, vivida pelo Brasil nas décadas anteriores. Essa defasagem se expressava tanto em relação às necessidades do desenvolvimento econômico quanto aos anseios da população. A expansão do capitalismo brasileiro encontrava alguns desacordos na política educacional de então que se materializavam na insuficiência da formação e da conformação da classe trabalhadora².

A análise da política educacional da ditadura empresarial-militar brasileira deve levar em conta os interesses dos diferentes setores que sobre ela se debruçaram. Ainda que possamos identificar frações de maior destaque na correlação de forças, diversos atores se organizaram em torno de seu projeto de educação e sociedade e desempenharam algum grau de pressão sobre a política governamental. Por trás do projeto vencedor encontravam-se as frações mais dinâmicas do capitalismo brasileiro, as agências internacionais e alguns setores internos à realidade educacional, que também incorporaram, de forma subordinada, aspectos selecionados e isolados dos projetos alternativos.

Dentre esses atores e organizações, existiam diversas nuances que os separavam, por um lado, e os aglutinavam, por outro, na disputa pelos rumos da política educacional. $\mathrm{Na}$ correlação de forças, damos especial destaque para 0 Instituto de Pesquisa e Estudos Sociais/IPES, não somente pela sua capacidade centralizadora dos interesses empresariais, mas sobretudo pela sua ingerência em postos estratégicos da política ditatorial. Analisamos o IPES como um partido político da burguesia multinacional e associada ${ }^{3}$ que, através de seus intelectuais

\footnotetext{
${ }^{2}$ A referência a essa defasagem entre educação e desenvolvimento não significa que o "atraso" econômico brasileiro se devesse à incapacidade educacional, visto que a própria limitação da educação também se originava na situação econômica. Na realidade, essa relação faz parte do contexto histórico que envolve a estrutura produtiva e também a luta de classes.

${ }^{3}$ Capital multinacional e associado é uma categoria, utilizada por Dreifuss (1981), para caracterizar uma fração da burguesia brasileira cuja dominação econômica remonta o governo de TrabalhoNecessario - www.uff.br/trabalhonecessario; Ano 15, №28/2017
} 
orgânicos, visava organizar os seus interesses enquanto fração de classe, de forma a construir uma vontade coletiva reconhecida não só por outras frações burguesas, mas também por parcelas da classe trabalhadora. (GRAMSCI, 2014; DREIFUSS, 1981).

Atuando a partir de diversas frentes, o Instituto esteve à testa da articulação do golpe e também da reestruturação do aparato político e econômico que se seguiria. Além de contribuir para a formação da consciência coletiva do empresariado como um todo e de sua ligação com as forças militares, agiu no sentido da mobilização da sociedade de forma a deslegitimar o presidente João Goulart e construir um clima favorável à dissolução do seu governo. Nos primeiros anos da ditadura empresarial-militar, fez parte da elaboração do planejamento econômico e educacional e também da articulação da sociedade civil em torno desses projetos em desenvolvimento.

Não obstante a caracterização do golpe como uma articulação da classe dominante, a burguesia não se constitui como um bloco monolítico de anseios homogêneos; ao contrário, existem diferentes frações em seu interior que se ligam de forma diferenciada a um mesmo processo de valorização de capital (CARCANHOLO; NAKATANI, 1999). No que se refere à educação, fundamentamo-nos na teorização de Rodrigues (2007), sobre educaçãomercadoria e mercadoria-educação para compreender as heterogeneidades de interesses entre os empresários ligados à indústria, organizados no IPES e os empresários de ensino, atuantes no âmbito das escolas particulares. Nessa análise, a mercadoria-educação se refere ao modo como ela serve para o capital produtivo, oferecendo profissionais qualificados ou semiqualificados a serem incorporados à produção. E a educação-mercadoria diz sobre o a condição em que a educação é ela própria uma mercadoria, manejada pelo capital comercial.

As formas de organização dos estabelecimentos particulares de ensino, nos anos de 1960, já possuíam considerável organicidade e poder de pressão. Ainda que não tenham protagonizado o golpe, as escolas particulares e suas associações se mostravam insatisfeitas com as práticas de João Goulart e

Kubistchek. A inserção do bloco multinacional, no Brasil, fez com que parte do capital brasileiro a ele tivesse que se associar para que pudesse coexistir no novo cenário de oligopólios.

TrabalhoNecessario - www.uff.br/trabalhonecessario; Ano 15, №28/2017 
receberam bem o novo governo que então se instalava. Nesse sentido, em função de sua força e também de sua longa história, os interesses desses setores compuseram também a correlação de forças que se materializaria nas políticas públicas de educação da ditadura. Ainda que, nesse período, seja difícil separar a defesa das escolas confessionais em relação às escolas laicas, nossa análise se debruça sobre os setores privados que se articulavam nos Congressos Nacionais dos Estabelecimentos Particulares de Ensino/CONEPES, um espaço privilegiado para organização e difusão de ideias ${ }^{4}$.

O presente trabalho se desenvolve no sentido de compreender os diferentes projetos educacionais defendidos, e implementados, pelas frações burguesas organizadas, no período da ditadura empresarial-militar brasileira. Observando que esse foi o período em que a educação seria colocada, mais diretamente, a serviço do capital, entendemos que as principais beneficiadas com a política educacional foram as frações que, associadas ao capital internacional, se ligavam ao setor produtivo e também a fração ligada à comercialização da educação. Observamos, nesse sentido, que os projetos das frações burguesas em destaque, ainda que distintos, não eram incompatíveis e puderam se adequar na materialização da política educacional do período.

Ainda que não possamos nos deter em cada um desses documentos, eles estão na base da articulação que aqui se tenta fazer acerca da relação entre os distintos interesses empresariais e a política educacional da ditadura empresarialmilitar brasileira. Com objetivo de empreender tal análise, o artigo se divide em duas partes, além da introdução e da conclusão. Na primeira parte, faremos uma abordagem mais teórica dos determinantes da educação no modo de produção capitalista, em especial na sua modalidade dependente, inserindo os projetos em questão nessa análise teórica. E, na segunda parte, nos debruçaremos sobre as leis n. 5.540/68 e n. 5.692/71, que reformam respectivamente a universidade e o então ensino de $1^{\circ}$ e $2^{\circ}$ graus, tendo em vista a correlação de forças a partir da qual elas foram implementadas.

\footnotetext{
${ }^{4}$ As escolas católicas também participavam dos congressos, mas a hegemonia era construída pelos empresários de ensino.
}

TrabalhoNecessario - www.uff.br/trabalhonecessario; Ano 15, №28/2017 
No período que aqui nos interessa - que se estende do golpe empresarialmilitar em 1964 até a lei 5.692 - o IPES realizou dois encontros para tratar dos rumos da política educacional. O primeiro deles foi um Simpósio sobre a educação, entre 1964 e 65, onde foi defendido o modelo estrutural norteamericano para as universidades, a leitura privatista de financiamento, a obrigatoriedade da educação física, o vinculo da educação com o mercado de trabalho, entre outras questões. (IPES, 1964a; IPES, 1964b) De maior ressonância no período, em outubro de 1968, foi realizado o Fórum "A Educação que nos Convém", que contava com a presença de diversos especialistas, empresários e políticos. (IPES, 1969)

Nesse mesmo intervalo de tempo, 1964-1971, foram realizados cinco Congressos Nacionais dos Estabelecimentos Particulares de Ensino. Em 1964, o oitavo congresso, realizou-se em Salvador e teve como tema a "Análise da Lei de Diretrizes e Bases". O nono congresso, realizado no ano de 1966 em Curitiba, debateu os "Aspectos Dinâmicos da Educação nos Graus de Ensino Primário, Secundário, Normal, Comercial e Industrial". Em fortaleza, no ano de 1967, foi feito o décimo congresso com o tema "Educação para o desenvolvimento". Em 1969, com o tema "A Educação Geral e a Educação Técnica", foi realizado no Rio de Janeiro o décimo primeiro congresso. E, por fim, o décimo segundo congresso teve como tema "As Novas Diretrizes e Bases da educação" e realizou em 1971 no Recife (CONEPE, 1964; CONEPE, 1966; CONEPE, 1967; CONEPE, 1969; CONEPE, 1971).

\section{Aproximações teóricas e históricas sobre a relação entre educação e realidade brasileira}

A negociação entre classes e frações de classe se constitui como um aspecto estruturante da relação de poder na sociedade capitalista. Quando se trata da educação, essa negociação assume determinações específicas que se referem às diversas demandas que o capital tem para ela, indo desde a formação da mão de obra até a difusão ideológica. Atravessando as demandas do capital, e delas fazendo parte, também interferem nos rumos da educação as lutas sociais 
que sobre ela depositam expectativas de melhoria das condições de vida e até mesmo de transformação social.

Para a sustentação material da ideologia burguesa, é importante que o sistema educacional se expanda, mesmo acima das necessidades produtivas, de forma a estabelecer, dentro dos limites, algum diálogo com as demandas da sociedade. Nesse sentido, as sociedades burguesas criam soluções - e tentam implementá-las - para os possíveis desajustamentos da ampliação do sistema educacional.

O projeto de sociedade que tinha no IPES um de seus principais centros articuladores estava vinculado ao modelo de desenvolvimento capitalista dependente, que imprime características específicas à periferia do capitalismo monopolista. Essa forma específica de desenvolvimento capitalista tem suas raízes em um passado colonial que se reconfigura a partir da reposição das relações de dependência, agora sob os marcos do capital. No entanto, tal processo não se delineia somente por imposições e pressões externas, mas também por decisões políticas internas de frações burguesas locais que veem na parceria com a burguesia hegemônica as condições para sua reprodução (FERNANDES, 2005).

Embora detenha localmente um poder extraordinário, exercendo a tirania burguesa de forma crua, sem disfarces, e utilize essa tirania para contar com níveis extremamente elevados de expropriação e de exploração, e embora - por sua condição de parceria desigual - tenha que partilhar seus lucros com as frações burguesas hegemônicas, nem assim essa burguesia se dispõe a se contrapor ao caráter dependente das estruturas capitalistas dentro das quais se encontra (CARDOSO, 2005, p. 25).

O capitalismo dependente é uma forma específica de capitalismo, mas que mantém características do passado colonial que lhe fundamenta. A condição colonial mostra-se como permanente e mutável; permanente porque marca a relação entre desenvolvimento capitalista e heteronomia, desde seu crescimento inicial, e mutável porque muda de forma a cada nova fase de seu processo de expansão. A condição de dependência é o próprio capital se expandindo a partir de uma incorporação diferenciada tanto nos ramos produtivos como nos setores sociais e regiões geográficas, promovendo um desenvolvimento cujo ganho se

TrabalhoNecessario - www.uff.br/trabalhonecessario; Ano 15, №28/2017 
concentra nos centros dinâmicos. A questão da autonomia/heteronomia não se pauta, dessa forma, por questões espaciais, mas pela (in)capacidade de decisão, direção, e gestão do processo de produção e reprodução do capital.

Essa relação de dependência, expressão local da dinâmica global de expansão do capitalismo monopolista, se manifesta em uma Revolução Burguesa descaracterizada, que não rompe com o passado, mas a ele se alia como forma de conter os elementos populares de uma ruptura estrutural. Dependendo, portanto, da fraqueza das classes trabalhadoras, economias dependentes, como a do Brasil, caracterizam-se pela redução da democracia, fundamentando uma sociedade profundamente desigual, onde a exclusão e a ausência de direito predominam nos setores que se encontram fora da classe dominante.

Estamos diante de uma burguesia dotada de moderado espírito modernizador que, além do mais, tendia a circunscrever a modernização ao âmbito empresarial e às condições imediatas da atividade econômica ou do crescimento econômico. Saía desses limites, mas como meio - não como fim - para demonstrar sua civilidade. Nunca para empolgar os destinos da nação como um todo, para revolucioná-la de alto a baixo (FERNANDES, 2005, p. 242).

A chamada "modernização conservadora", que revoluciona pelo alto, foi a marca do desenvolvimento capitalista brasileiro ${ }^{5}$, cuja maturidade se atingiu na década de 1960 e tinha no IPES a sua expressão política interna principal. As especificidades da educação no capitalismo dependente atingiram, desse modo, não somente a política e a realidade educacional brasileiras, mas também a própria classe dominante que chamava a educação a resolver seus problemas.

$\mathrm{Na}$ realidade, podemos dizer que o capitalismo dependente exacerba as contradições que tem a educação no próprio capitalismo, como o dualismo de sistemas e a sua subsunção ao capital. Isso porque a reprodução do capital, periférica ou central, envolve a reprodução da força de trabalho, não somente daqueles que estão na ativa, mas também daqueles que constituem o exército industrial de reserva. (BRUNO, 2011).

\footnotetext{
${ }^{5}$ A modernização conservadora caracteriza-se pela articulação de um pacto político entre burguesia e oligarquias tradicionais, a partir do qual a sociedade capitalista se reproduz preservando formas pretéritas de dominação (MOORE, 2010 apud SILVEIRA, 2011, p. 126).
}

TrabalhoNecessario - www.uff.br/trabalhonecessario; Ano 15, №28/2017 
$\mathrm{Na}$ medida em que a tecnologia se desenvolve, a complexificação do trabalho passa a exigir mais da educação, cuja formação deve servir para que o trabalhador acompanhe a constante transformação da maquinaria e devolva com o nível necessário de produtividade. No entanto, não é somente o pragmatismo econômico que envolve essa relação, ao passo que a escola também é tida como um espaço de (con)formação da sociabilidade capitalista, em suas especificidades temporais e regionais.

Como parte dessa sociabilidade, temos que no capitalismo, ao contrário de anteriores modos de produção, a classe dominante se reproduz incorporando outras frações de classe ao seu nível cultural, tanto para formar seus intelectuais e dirigentes, quanto para fundamentar a ideologia do mérito que diz sobre o trânsito entre as classes sociais. $O$ capitalismo expande, desse modo, a educação formal por diversas razões; além da pressão da classe trabalhadora, a demanda por qualificação e a (con)formação ideológica tem na escola um de seus espaços privilegiados. A forma e a quantidade que a educação irá se subsumir à dinâmica do capital depende do modo como as frações burguesas se desenvolvem no interior da correlação de forças. Quanto mais permeáveis são, os centros de pensamento, à colaboração de agências privadas, mais fácil se torna a difusão ideológica.

Por um lado, o sistema escolar capitalista termina por reproduzir, através do dualismo educacional, o seu sistema de classes, seja em sociedades mais ou menos democráticas. Por outro, condicionantes históricos específicos colocam determinações igualmente específicas para a educação. Isso é o que ocorre nas sociedades de economia dependente.

Primeiramente, pesa nas economias dependentes a predominância, até muito tardiamente, da extração da mais valia absoluta, cuja expansão se dá através da ampliação do trabalho simples e pouco exige de instrução (BRUNO, 2011). Até meados da década de 1950, essa era a condição no Brasil; na medida em que a indústria ainda se encontrava minoritária na economia, essa reclamava à educação uma expansão limitada. Com a inflexão sofrida no governo Kubistchek, a industrialização dá um novo salto de expansão e supera a agricultura em participação no Produto Interno Bruto. No entanto, isso não 
significa a superação da mais valia absoluta ou a universalização do trabalho complexo, mas coexistência das diferentes formas de exploração, muitas vezes em uma mesma cadeia produtiva ${ }^{6}$. Essa composição hierárquica nas relações de trabalho se expressa também na composição e na trajetória escolar, compondo o dualismo educacional que se manteve mesmo após as reformas dos anos $1960 .^{7}$

Em segundo lugar, destacamos a despreocupação com a nação por parte dos países de capitalismo dependente, nos quais "a nação não chega a ser definida como um objetivo central do desenvolvimento capitalista, invariavelmente centrado em (...) fundir os desígnios dos estamentos ou das classes dominantes com os fins econômicos e extraeconômicos da dominação imperialista externa" (FERNANDES, 2005, p. 263). Disso decorre uma educação negligente com a cultura nacional e o desenvolvimento cultural autônomo, que tem na universidade a expressão mais sofisticada de sua heteronomia - local onde a ciência cede lugar à adequação tecnológica.

Depreende-se que a condição capitalista dependente tem como consequência uma pequena demanda de cientistas e engenheiros, por isso as universidade não ocupam papel estratégico. A adequação tecnológica, algo inevitável para a implementação de plantas industriais e do setor de serviços, como é episódica, acaba sendo desviada para as universidades que, desse modo, tem suas funções ressignificadas, pois entram no circuito do capital de forma imediata e pontual, impedindo tanto a autonomia em P\&D como a expansão e a melhoria das universidades públicas (LEHER, 2005, p. 240-1).

Por fim, cabe apontar que, combinado a essa despreocupação com a nação, o ideal de desenvolvimento aparece como a promessa de superação não da dependência, mas do subdesenvolvimento ${ }^{8}$. A partir dessa interpretação da condição das periferias, as desigualdades mundiais são atribuídas à propagação diferenciada do progresso técnico, a ser superada através da incorporação de

\footnotetext{
${ }^{6}$ Chamamos atenção para o fato de que não há uma separação estanque, a partir da qual a agricultura extrai mais valia absoluta, enquanto a indústria extrai a relativa. Há uma combinação de explorações tanto em um setor produtivo quanto em outro, fruto da industrialização da agricultura e do trabalho coletivo na indústria.

${ }^{7}$ Novamente, não queremos dizer que essa composição não exista em países de capitalismo central, mas que na periferia suas características ficam mais acentuadas.

${ }^{8}$ Entendemos que a própria caracterização de subdesenvolvimento traz implícita uma ideia de linearidade histórica inquestionável que retira das relações sociais a responsabilidade sobre as desigualdades existentes. Nessa perspectiva, as sociedades estariam em diferenciados estágios de desenvolvimento, a serem superados por escolhas e investimentos adequados.
}

TrabalhoNecessario - www.uff.br/trabalhonecessario; Ano 15, №28/2017 
tecnologia avançada de modo articulado à formação da mão de obra adequada à atividade em expansão. Adequação essa que impõe não somente limites para a extensão da escolarização, mas também desigualdade para o sistema escolar existente.

$\mathrm{Na}$ especificidade da sociedade brasileira, como em grande parte dos países de capitalismo dependente, o desenvolvimento desigual e combinado com setores produtivos "atrasados" imprime, no âmbito da educação, além da profunda dualidade escolar, um retrocesso nos princípios burgueses republicanos. A universalização se reveste em massificação, mas do tipo periférico, ainda mais minimalista (MOTTA; MAGALHÃES, no prelo, p. 4).

A condição de dependência se manifesta na educação e nos projetos educacionais daqueles que querem reproduzi-la, como era o caso do IPES. Nesse sentido, a valorização do fator humano, através da formação educativa, estava acompanhada de uma despreocupação com o desenvolvimento do conhecimento científico autônomo. A preocupação central era a formação de mão de obra capaz de operar a tecnologia importada. No interior do projeto de sociedade, portanto, capitaneado pelas frações multinacionais e associadas, se encontrava um ideal de educação fruto de uma forma específica de apropriação da Teoria do Capital Humano. Dizemos "apropriação específica” por entender que a mesma teoria serve para justificar projetos educacionais distintos, em um país como os Estados Unidos da América e um país de capitalismo dependente, como o Brasil.

Em sentido amplo, podemos dizer que a Teoria do Capital Humano atribui parte do desenvolvimento econômico à formação e qualificação do trabalho, responsáveis pelo aumento da produtividade industrial. A partir dessa perspectiva, do investimento em educação decorreria crescimento econômico para os países e ampliação das rendas para os indivíduos, os quais poderiam vender de maneira mais vantajosa o seu próprio capital $^{9}$, a força de trabalho qualificada. A partir dessa análise econômica defendia-se que, em benefício de todos, a educação

\footnotetext{
${ }^{9} \mathrm{~A}$ defesa de que todos podem ser portadores de capital tem por traz uma compreensão ahistórica das relações sociais, a partir da qual a exploração da sociedade capitalista aparece como uma troca entre seres livres e iguais.
}

TrabalhoNecessario - www.uff.br/trabalhonecessario; Ano 15, №28/2017 
deveria se voltar para o desenvolvimento econômico e as necessidades do mercado. Nas palavras de Schultz:

Os trabalhadores transformaram-se em capitalistas, não pela difusão da propriedade das ações da empresa, como o folclore colocaria a questão, mas pela aquisição de conhecimentos e de capacidades que possuem valor econômico. Esse conhecimento e essa capacidade são em grande parte o produto de investimentos e, combinados com outros investimentos humanos, são responsáveis predominantemente pela superioridade produtiva dos países tecnicamente avançados (SHULTZ, 1973, p. 35).

A Teoria do Capital Humano surge em um país de capitalismo central, nos EUA, para explicar a desigualdade econômica entre nações e também os diferenciais de renda entre os indivíduos, com base nos investimento em educação. Ao explicar as razões do subdesenvolvimento, servia também como um guia para sua superação e assim foi incorporada em diversos países periféricos. No entanto, o que essa teoria deseja explicar é menos elucidativo do que acaba por esconder. Quando relaciona direta e proporcionalmente educação e desenvolvimento, ela está captando um sintoma e não desvelando uma relação causal, como pretende fazer. A suposta causalidade serve, porém, ao obscurecimento das relações capitalistas que estão na base não somente da desigualdade, mas também do baixo rendimento educacional.

Em conformidade com o que viemos analisando até aqui, o projeto educacional das frações multinacionais e associadas, organizadas no IPES, propunha uma vinculação da educação com o mercado e com as demandas do desenvolvimento econômico. Na esteira da Teoria do Capital Humano, entendiam que o problema do Brasil estava na escassez dos recursos humanos demandados pelo processo produtivo, submetendo a educação não só capital, mas ao capital em sua modalidade dependente.

O Estado era chamado a mediar a socialização dos custos da formação da força de trabalho e do aumento da produtividade do capital. Para tanto, era necessário a construção de uma política de educação que não só se estruturasse a partir das demandas do mercado, mas que também garantisse aos empresários o controle sobre o ensino. É a partir desse viés que as propostas 
eram feitas, centradas na reestruturação educacional e na participação empresarial, tanto nas políticas de financiamento quanto nos órgãos decisórios.

Em termos estruturais, o projeto educacional do IPES defendia a necessidade de aproximar o então nível médio das relações de trabalho, combinando qualificação com conformação social, mas não ausentando as indústrias da participação nessa formação. Ao mesmo tempo, pedia por uma expansão controlada do ensino superior, de modo que pudesse atender às novas funções em desenvolvimento, sem onerar desnecessariamente o fundo público. Ainda nesse nível, o papel da pesquisa é elucidativo, pois quando não se via negligenciada em prol da formação dos operadores da tecnologia importada, era submetida às necessidades dos setores ligados ao modelo de desenvolvimento dependente. Em suma, podemos entender que, a partir desse projeto, a educação deveria se colocar a serviço do desenvolvimento econômico brasileiro vinculado à dinâmica global imperialista, gozando de reduzida ou nenhuma autonomia.

Não obstante a ingerência do referido projeto nos aparelhos de Estado, devemos destacar que ele não foi contemplado por inteiro e que foi também atravessado pelas pressões de seus opositores. Na perspectiva de construção de um projeto suficientemente articulado, o IPES tomava a frente na defesa de demandas que the eram externas, adequando-as e relativizando-as de acordo com seus interesses. Na realidade, a própria necessidade de expandir o atendimento educacional, médio e superior, derivava não somente do mercado de trabalho, mas também da pressão da população urbana em expansão ${ }^{10}$.

No entanto, pensando nas funções que a educação formal pode ter ao capital - formação para o trabalho e (con)formação da sociabilidade burguesa -, as pressões externas ao empresariado podem ser atendidas em conformidades com os seus interesses. A expansão educacional, além do necessário, pode ser compensada através da desqualificação de algumas, ou muitas, de suas instituições e da criação de novas hierarquias internas ao sistema de ensino. Quando os empresários do IPES defenderam os cursos de curta duração e o fortalecimento da pós-graduação, por exemplo, eles estavam criando novos

\footnotetext{
${ }^{10}$ Um exemplo disso é a referência à demanda de técnicos de nível médio, colocada inclusive pelo IPES, mas que não havia nenhum estudo que comprovasse ou identificasse a intensidade dessa falta (CUNHA, 1973).
}

TrabalhoNecessario - www.uff.br/trabalhonecessario; Ano 15, №28/2017 
mecanismos de reproduzir a estrutura de classes mesmo com uma expansão do ensino superior indesejada, mas incontornável frente ao movimento da Reforma Universitária.

A improdutividade da escola parece constituir, dentro desse
processo, uma mediação necessária e produtiva para a
manutenção das relações capitalistas de produção. A
desqualificação da escola, então não pode ser vista apenas como
resultado as falhas dos recursos financeiros ou humanos, ou da
incompetência, mas como uma decorrência do tipo de mediação
que ela efetiva no interior do capitalismo monopolista (FRIGOTTO,
1984, p. 134).

Como afirma Frigotto (1984), a improdutividade da escola não é uma consequência residual de um sistema desigual, mas uma das condições para sua reprodução, que se materializa em escolhas políticas que negligenciam o financiamento e sua autonomia. A limitação da escola não era, desse modo, descritiva e sim prescritiva, atuando de forma que a educação pudesse ser retirada da mão de seus agentes e se restringisse aos interesses empresariais.

É também na intersecção dessas funções educacionais que vemos a possibilidade de conformação dos interesses dos empresários industriais e empresários de ensino, dando aos últimos a possibilidade de manejar o tipo formação oferecida dentro de suas necessidades corporativas.

Os empresários de ensino, que se organizavam nos CONEPEs, não possuíam um projeto de sociedade definido, mas integravam os seus interesses corporativos ao projeto hegemônico, desde que estivesse em sintonia com a sua reprodução enquanto classe. No período de 1964-71, isso foi o que aconteceu; as sistematizações dos CONEPEs incorporaram a Teoria do Capital Humano e a partir dela organizaram a sua defesa que incidia, principalmente, sobre a liberdade de ensino e as subvenções públicas para as escolas particulares. Houve, no entanto, um momento de maior tensionamento quando, no debate sobre a profissionalização do ensino médio, os empresários não puderam esconder a sua insatisfação com uma política que elevaria sobremaneira os seus custos (CONEPE, 1967). Apesar da pressão, eles não tiveram força suficiente para travar o processo em curso e a ele tiveram que, ao menos temporariamente, se adaptar (CONEPE, 1971).

TrabalhoNecessario - www.uff.br/trabalhonecessario; Ano 15, №28/2017 
Não obstante, a necessidade de ceder à legislação não significou uma derrota para os empresários de ensino, mas apenas uma intercorrência com a qual eles teriam de lidar. A forma como a legislação iria se materializar na realidade educacional era ainda mais importante. Outras soluções foram criadas e a correlação de forças também se reconfiguraria. A forma como as frações de classe analisadas buscaram conduzir a legislação e a realidade educacional, em meio a um processo que envolvia toda a sociedade, é o que nos interessa no ponto a seguir.

\section{As reformas educacionais da ditadura}

No período em análise, destacamos que tanto a burguesia quanto os trabalhadores chamavam, com finalidades diferentes, pela adequação da educação ao contexto social e econômico. Tentando evitar intercorrências, as frações empresariais multinacionais e associadas - que mais organicamente se entendiam enquanto classe e tinham no IPES sua instituição articuladora buscaram controlar a expansão educacional, atrelando-a aos seus interesses e tirando-Ihe a autonomia. Desse modo, tentaram construir um sistema educacional que fosse capaz de apaziguar as animosidades e oferecer, ao mercado de trabalho, os profissionais exigidos. Fazem parte, no entanto, desse campo profissional não somente a mão de obra qualificada, mas também aqueles que devem ter em sua história educacional uma contínua desqualificação para o trabalho combinada a uma conformação com a sua condição.

Essa "produtividade da escola improdutiva" (FRIGOTTO, 1984) se faz sentir, principalmente, nos níveis iniciais de ensino, mas se mantém nos seguintes, conforme a expansão da educação atinge, do ponto de vista da produção capitalista, desnecessariamente os outros níveis de escolarização. Desse modo, com o desenvolvimento do capitalismo, a manutenção da desigualdade educacional toma uma nova face: não abandonando a exclusão direta de parte da classe trabalhadora aos mais altos graus de ensino, a desigualdade passa a se reproduzir também a partir da hierarquização das instituições escolares. 
A ampliação hierarquizada das matrículas escolares é produtiva, para classes dominantes, não somente para a sua sustentação ideológica em relação à classe trabalhadora, mas também para a reprodução do exército de reserva um dos responsáveis pela regulação salarial. Com isso, não queremos dizer que as lutas pela educação de nada valem ou só beneficiem a reprodução do capital, mas que as classes dominantes estão sempre se reposicionando de modo a tentar contornar as lutas sociais, por meio da repressão ou da tutelagem de suas reivindicações.

É no entrecruzamento dessas lutas em torno educação que as frações burguesas buscam conformar os seus interesses heterogêneos, se adaptando às diferentes funções da educação para a reprodução das relações capitalistas. Nesse trabalho, privilegiamos as proposições do IPES e dos CONEPEs, na perspectiva de analisar o modo como as frações burguesas, neles organizadas, construíram seu projeto educacional em meio aos debates que então se faziam e envolviam toda a sociedade.

Vimos, dessa forma, como o IPES integrou a educação ao seu projeto de classe e desenvolvimento econômico, enquanto os CONEPEs representavam os ideais corporativos de uma fração de classe disposta a incorporar o projeto de sociedade hegemônico, se a partir dele pudesse garantir a manutenção de seus lucros. As políticas públicas aqui analisadas materializaram as perspectivas dos dois setores e tiveram como principais consequências, justamente, o recrudescimento da mercantilização da educação e a inflexão tecnicista dos currículos (SAVIANI, 2008).

No entanto, não foram somente essas organizações que se debruçaram sobre a reforma educacional. Além do movimento estudantil, as agências internacionais, os educadores e os militares compuseram, igualmente, o cenário da reforma. De alguma forma, esses atores incidiram sobre a nova legislação e deixaram também sua marca nas proposições das organizações aqui analisadas. Vejamos agora um pouco do contexto e das principais forças que compuseram a formulação da Reforma Universitária e da Reforma do ensino de $1^{\circ}$ e $2^{\circ}$ graus.

\section{A Reforma Universitária de 1968}

TrabalhoNecessario - www.uff.br/trabalhonecessario; Ano 15, №28/2017 
No que tange o ensino superior, e mais especificamente a universidade, os anos 1960 assistiram um acirrar de posições em termos de qual seria o seu papel. Tudo isso animado pelo movimento que ganhou fôlego já no início dessa década, a partir de crescente engajamento político, com o protagonismo da UNE e dos CPCs. Suas principais bandeiras eram a democratização do acesso; a extinção da cátedra vitalícia; autonomia universitária, compromisso social e o co-governo nos órgãos colegiados. Somado a isso, aparecia o problema dos excedentes ${ }^{11}$, ou seja, de pessoas que estavam aptas ao ingresso no ensino superior, mas que se encontravam limitadas pelo número reduzido de vagas. No entanto, esses não eram os únicos atores engajados com o direcionamento do ensino superior brasileiro.

Nos polos do debate se encontravam, de um lado, aqueles defensores da universidade crítica e implicada com os problemas conjunturais e estruturais e, de outro, aqueles que temiam tal engajamento, negando que sua própria concepção fosse de alguma forma engajada. Entre os polos, encontravam-se uma série de posições das quais se destaca a concepção liberal de universidade, comprometida com a multiplicidade de formas de conhecimento e também com a ciência desinteressada (CUNHA, 1988).

O golpe de 1964, além da feroz repressão, representou o engajamento da universidade na modernização do capitalismo brasileiro, aproximando-a do modelo norte-americano, não só pelos departamentos e sistemas de crédito, mas por um novo ethos mais pragmático. No entanto, essa diretriz precisou ser adaptada e conformada aos projetos em disputa, ainda que sob a hegemonia do projeto tecnocrático, que tinha no IPES um de seus principais espaços de difusão (LEHER, 2013).

Em termos mais amplos, a reforma precisou dialogar com as demandas do movimento estudantil e setores universitários resistentes, ao mesmo tempo em que consolidava os interesses dos grupos ligados ao regime que compunham o

\footnotetext{
${ }^{11}$ Essa questão se relaciona com a LDB, de 1961, que havia equiparado os ensinos secundário e técnico para o ingresso no ensino superior, o que gerou forte pressão sobre a universidade.
}

TrabalhoNecessario - www.uff.br/trabalhonecessario; Ano 15, №28/2017 
bloco no poder - com maior expressão, destacamos o IPES e as agências internacionais, mas também alguns setores universitários apoiadores.

Com algumas formulações atentas às demandas estudantis, o relatório elaborado pelo Grupo de Trabalho ${ }^{12}$ responsável pela reforma aboliu as cátedras vitalícias, proclamou a indissociabilidade entre ensino e pesquisa, a autonomia universitária e elegeu a universidade como forma de organização preferencial. Ainda nessa perspectiva de construção do consenso, mesmo em um período de radicalização da coerção em relação aos estudantes, a Reforma universitária acabou por restabelecer a sua participação nos colegiados superiores, ainda que com diversas limitações.

A Reforma Universitária de 1968, desse modo, ainda que tenha sido elaborada sob a hegemonia dos interesses multinacionais e associados, precisou dialogar com os amplos setores que construíram o movimento para sua elaboração; dentre esses setores encontrava-se o movimento estudantil. Combinando repressão às entidades estudantis combativas, contemplação de alguns interesses dos estudantes e adaptação discursiva, a tentativa de construção do consenso permeou não somente a atividade do governo, mas também esteve presente, como vimos, no próprio projeto educacional organizado pelo IPES. Nada disso deve, logicamente, obscurecer o caráter autoritário da reforma e do arranjo político que a legitimou.

É preciso que fique bem claro, de antemão, que entendemos a reforma universitária consentida como uma manifestação de tutelagem política e como mera panaceia. Não podemos aceitá-la porque ela não flui de nossa vontade, não responde aos anseios que animam as nossas lutas pela reconstrução da universidade e não possui fundamentos democráticos legítimos (FERNANDES, 1975, p. 204).

A despeito das negociações, tanto a lei 5.540/68 quanto a lei 5.692/71 foram norteadas pela tendência tecnicista de educação, já vivenciada em outros países do globo. Segundo as recomendações dos organismos supranacionais, em conformidade com as organizações nacionais da elite orgânica, a

\footnotetext{
${ }^{12}$ Institucionalmente, o processo de formulação da Reforma Universitária se iniciou em meados de 1968 quando, em 2 de julho, foi baixado o Decreto no 62.937 o qual mandava instituir um grupo de trabalho para estudar a reforma do ensino superior, composto por 11 membros, designados pelo presidente, além do ministro da educação. (CUNHA, 1988)
}

TrabalhoNecessario - www.uff.br/trabalhonecessario; Ano 15, №28/2017 
universidade deveria se voltar para a formação de recursos humanos, a ser garantida pelo controle empresarial sobre a Universidade.

As concessões representaram um engodo em função do qual as reformas, que interessavam às classes dominantes, puderam se consolidar. A partir de sua vertente pragmática, o relatório do Grupo de Trabalho instituiu o sistema de créditos, as matrículas por disciplina, os cursos de curta duração e a racionalização da estrutura e funcionamento. Aprovado no congresso, os aspectos "prejudiciais", principalmente relacionados à autonomia, foram vetados pelo presidente. A composição múltipla do GT conformou uma reforma que se justificava por um idealismo em relação à universidade, mas que, na prática, abria espaço para a transformação inspirada pelo modelo norte-americano; modelo esse que pode ser assim definido:

Em síntese, o modelo norte-americano põe ênfase no progresso, convergindo a aspiração dos indivíduos da sociedade para o saber que interessa ao desenvolvimento econômico, buscando, desse modo, associar estritamente os aspectos ideais - ensino e pesquisa - e o aspecto utilitário - serviço à comunidade - aos aspectos funcionais da sociedade, aspectos contemplados, ontem e hoje, em uma multiplicidade de cursos de graduação e pósgraduação de longa e curta duração, oferecidos por diferentes instituições (SILVEIRA, 2011, p. 230).

Esse modelo de universidade interessava às frações da burguesia brasileira ligadas ao movimento internacional do capitalismo monopolista, mas já vinha conquistando adeptos no interior das universidades e na sociedade como um todo. Fazendo parte da agenda internacional de modernização das universidades, a educação como fator de desenvolvimento conformava interesses diversos num contexto em que o projeto desenvolvimentista havia logrado a hegemonia. Ainda que esse projeto possuísse mais de uma vertente, principalmente no que toca a questão do capital internacional, a reforma do ensino superior conseguiu obscurecer a sua incorporação subordinada na dinâmica imperialista, colocando em destaque os aspectos que modernizavam a 
estrutura universitária em detrimento da autonomia reivindicada por projetos de esquerda e até liberais ${ }^{13}$.

A Reforma combinou uma inflexão no sentido do modelo norte-americano não somente em estrutura, mas em função de um ethos mais pragmático - com a matriz autoritária do modelo alemão. Isso porque o controle empresarial sobre o ensino superior passou a se dar não somente por meio dos investimentos diretos e da participação nos órgãos diretivos, mas também pela repressão sobre professores e estudantes inadequados e resistentes ao novo funcionamento. (LEHER, 2005).

Em conformidade com o projeto de educação do IPES, do qual fazia parte a negociação com setores resistentes, o processo de reforma teve de lidar com a contradição da expansão, que se expressava no conflito entre o ensino de massas e a sua condição histórica seletiva. Nesse sentido, o ensino superior foi colocado como seletivo por sua própria natureza e mantenedor da alta cultura, que permanecia como privilégio de alguns. Não obstante, na perspectiva de absorver ao menos uma parte do crescente fluxo de candidatos, a solução encontrada foi a "diversificação vertical", com a fragmentação do grau acadêmico de graduação e a pós-graduação ${ }^{14}$.

A hierarquização de graus e instituições de ensino é, como já foi comentado, um dos mecanismos que as sociedades capitalistas criaram para atender às demandas da população pela expansão educacional ao mesmo tempo em que se mantém e se reproduz a estrutura de classes, por meio do dualismo educacional. A materialização do dualismo tem como um de seus principais pressupostos a distribuição desigual dos recursos, ou até mesmo a negligência em relação a eles.

Nesse caso, por exemplo, a lei e o grupo de trabalho fixaram que a estrutura privilegiada, para o ensino superior, era a universitária. Além disso, rejeitaram que a quantidade prejudicasse a qualidade. Mas como implementar essas orientações ao mesmo tempo em que a constituição retirava a vinculação de percentuais mínimos da União para a educação? Como manter a qualidade,

\footnotetext{
${ }^{13}$ Isso não significa uma ausência de resistência em relação à reforma, mas que conseguiu se legitimar sem muitas críticas destinadas a elas.

${ }^{14}$ O Parecer ํㅜ 77, de 1969, regulamentou o sistema nacional de pós-graduação.

TrabalhoNecessario - www.uff.br/trabalhonecessario; Ano 15, №28/2017
} 
quando a diretriz máxima é a racionalização? Complementando o que a lei prescreveu, o não dito compôs, igualmente, a reforma universitária que seria vivida na prática. "O sentido da transformação do ensino superior, na linha da paroquialização, da fragmentação e da privatização, fez com que a esperança do GT fosse atropelada pelos fatos, co-determinados pela própria política do CFE de abrir caminho para a multiplicação das escolas isoladas" (CUNHA, 1988, p. 246).

Mantendo núcleos de pesquisa avançada e de formação da elite dirigente, a expansão do ensino superior que o movimento estudantil exigia foi feita, no entanto, através das escolas isoladas privadas e da desqualificação de determinados núcleos das universidades oficiais (SAVIANI, 2010). Paralelamente, era necessário conter a ampliação excessiva das vagas em função das demandas do mercado, para que os estudantes excedentes não fossem substituídos por profissionais excedentes, de nível superior. Foi com a perspectiva de conter a demanda sobre o ensino superior que o grupo de trabalho propôs a organização de um ginásio comum e um colégio integrado; proposição que viria a compor a reforma seguinte no tocante à estrutura do então ensino primário e médio.

\section{A Reforma do ensino de $1^{\circ}$ e $2^{\circ}$ graus de 1971}

A ditadura empresarial-militar brasileira contava com forte aparato repressivo, mas que não se mostrou suficiente para a contenção dos conflitos sociais em geral, e do movimento estudantil, em particular. A década de 1960, mesmo após o golpe de 1964, assistiu o recrudescimento da organização estudantil em torno da expansão da educação e da melhoria de suas condições, principalmente no que se refere ao ensino superior. Ainda que a Reforma Universitária tenha conseguido contentar a uma parte do movimento e, em articulação com o Ato Institucional $n^{\circ} 5$, silenciar a outra parte, estava claro que ela não seria capaz de conter a pressão sobre o ensino superior. Somado a isso, os setores produtivos reclamavam uma adequação também dos níveis primário e médio às suas demandas.

Tendo isso em vista, o presidente Costa e Silva nomeou, ainda em 1969, uma comissão de 32 membros encarregada de reestruturar esses níveis de 
ensino. No entanto, somente em 1970 que os trabalhos se iniciaram quando, através do Decreto $\mathrm{n}^{\circ}$ 66.600, um novo grupo foi formado com a responsabilidade de propor medidas para atualização e expansão dos níveis fundamental e médio. O anteprojeto foi encaminhado à presidência em 30 de março de 1971, o qual seguiu para o Congresso Nacional em 29 de junho do mesmo ano. Em 11 de agosto de 1971, foi promulgada a Lei no 5.692/71, que estabeleceu as bases legais no ensino de $1^{\circ}$ e $2^{\circ}$ graus.

O Grupo de Trabalho, instituído em 1970, pelo então ministro da educação Jarbas Passarinho, era composto por nove membros, dentre os quais se destaca o seu presidente - o Padre José de Vasconcelos. Na ocasião, também presidente da Associação das Escolas Católicas, a sua presença demonstra uma organicidade ainda persistente da igreja católica no quadro de formulação das políticas educacionais. Através dessa ingerência, a reforma contemplou o ensino religioso, ainda que facultativo nas escolas oficiais, e o amparo técnico e financeiro às escolas particulares ${ }^{15}$ (LIRA, 2010). Não obstante, as linhas gerais da nova legislação coadunavam, mais diretamente, com os ideais tecnicistas do empresariado industrial.

A partir da lei $n^{\circ} 5.692 / 71$, o ensino primário e o $1^{\circ}$ ciclo do ensino médio passaram a integrar o $1^{\circ}$ grau que, dos 7 aos 14 anos, se tornava obrigatório e $2^{\circ}$ ciclo do médio se tornava o $2^{\circ}$ grau. Além disso, a nova lei teve como uma de suas principais iniciativas a fusão dos ramos do antigo ensino médio secundário, industrial, normal, agrícola e comercial - em um só, todo ele profissionalizante. No primeiro grau, que passava a englobar o ensino primário e ginasial, já haveria uma sondagem de aptidões e até uma iniciação para o trabalho.

A profissionalização do segundo grau, somada à ampliação da obrigatoriedade de escolarização de 4 para 8 anos, era encarada como uma abertura de oportunidades. Ao mesmo tempo, a nova estrutura era vista, ainda que não declaradamente, como uma forma de resolver o problema dos excedentes, já que todos que completassem o $2^{\circ}$ grau estariam habilitados para

\footnotetext{
${ }^{15}$ Como vimos em outro momento, os empresários de ensino que participaram do XII CONEPE, já mostrando relativa independência em relação à igreja católica, não estavam satisfeitos com a profissionalização e disputavam o fundo público como forma de implementá-la.
}

TrabalhoNecessario - www.uff.br/trabalhonecessario; Ano 15, №28/2017 
algum tipo de trabalho; e, mesmo com $1^{\circ}$ grau, já teriam passado por algum tipo de iniciação facilitadora da integração ao mercado de trabalho (SILVEIRA, 2010). Essa função de contenção da demanda não fica explícita na lei da profissionalização por razões ideológicas, onde a frustração aparece como consequência do despreparo para o trabalho e não em função do fracasso na perspectiva de ascensão social.

De forma declarada, a justificativa manifesta da profissionalização era a necessária "terminalidade" do ensino médio que, a partir da produção de uma habilitação, poderia conter a frustração daqueles que se viam rejeitados pelo processo seletivo do vestibular. Nesses termos, a procura pelo ensino superior estaria relacionada com a insuficiência do ensino médio na preparação profissional. Contrariamente, Cunha (1973) defende que o ensino superior tinha o seu próprio "valor" e que sua procura se relacionava com as perspectivas de ascensão social e não somente com a busca de uma habilitação. Não obstante, em meio às tensões que se colocavam em torno da temática educacional, essa lei veio acalmar os ânimos e, de certa forma, pouca resistência sofreu em seu processo institucional.

O relativo consenso que se firmou em relação a essa nova política de educação pode ser explicado pelo contexto em que ela foi formulada, no qual a ditadura gozava de certa legitimidade, em função do chamado milagre econômico. Também foi o período em que a repressão pode contar com um novo instrumento institucional, o Al nำ, e que a resistência se concentrava nas táticas guerrilheiras, pouco apreciadas pelo conjunto da sociedade. Tudo isso possibilitou que a atualização do ensino fundamental e médio pudesse transcorrer sem maiores sobressaltos ${ }^{16}$ (GERMANO, 1993). O contexto do milagre econômico também ajuda a explicar os determinantes econômicos que embasaram a reforma; contexto esse que reclamava a ampliação da oferta de $1^{\circ}$ grau - a partir do qual se alcançava uma formação mínima para a classe trabalhadora - e também a preparação de um núcleo de mão de obra qualificada.

Nesse sentido, a análise da lei 5.692 desvela o caráter classista dessa política; isso porque a prevista possibilidade de iniciação ao trabalho no $1^{\circ}$ grau $(8$

\footnotetext{
${ }^{16} \mathrm{O}$ mesmo não podemos dizer sobre a sua aplicação, mas a isso voltaremos em outro momento.
}

TrabalhoNecessario - www.uff.br/trabalhonecessario; Ano 15, №28/2017 
anos, dos 7 aos 14) se relacionava com a impossibilidade de permanência dos estudos por uma parte da população, sendo, portanto, necessária a terminalidade real ainda nessa etapa escolar. Essa lei, articulada à reforma universitária, foi a expressão máxima da luta de classes, em função da qual o bloco no poder tentou dar conta dos anseios da classe trabalhadora subjugando-os às demandas do capital. Formando e conformando ${ }^{17}$, hierarquicamente, os trabalhadores, a nova estrutura educacional se responsabilizava por oferecer ao mercado os profissionais exigidos para compor o exército produtivo e também o exército de reserva. Os inconvenientes de uma expansão educacional excessiva, para as necessidades do mercado, poderiam ser resolvidos na prática de uma escolarização desigual.

Como vimos nos documentos elaborados pelo IPES, os empresários tinham uma demanda seletiva de trabalhadores qualificados, ao mesmo tempo em que não consagravam a escola formal como o espaço privilegiado de formação para o trabalho. No entanto, não era possível, sem colocar em risco a própria estrutura de poder, travar a expansão educacional. A solução que despontava era o controle sobre um processo inevitável. Os empresários do IPES articularam uma defesa que colocava as empresas em papel de colaboração com a habilitação profissional, oferecida pelas escolas. Essa orientação se formalizou na legislação e compôs o cenário de subsunção da educação à dinâmica de reprodução do capital.

A expansão, e até universalização, da educação escolar é uma condição histórica da complexificação das sociedades burguesas por duas razões principais: por um lado, a própria burguesa demanda níveis de formação compatíveis com as diversas categorias profissionais requeridas pela indústria e, por outro, a classe trabalhadora reivindica a escola como um espaço propiciador de melhores condições de vida, em conformidade com o mito meritocrático da ideologia burguesa ${ }^{18}$. Como nenhuma ideologia se sustenta sem uma base material, a burguesia, muitas vezes, se vê impelida a estender a escolarização

\footnotetext{
${ }^{17}$ Cabe apontar que a Educação Moral e Cívica, que já integrava o currículo desde 1968, teve seu programa elaborado oficializado em 1971, por meio do parecer no 94/71.

${ }^{18} \mathrm{~A}$ luta pela expansão escolar pode também se integrar a uma luta geral pela transformação geral da sociedade.
}

TrabalhoNecessario - www.uff.br/trabalhonecessario; Ano 15, №28/2017 
para além de suas próprias necessidades. Quando isso acontece, as classes dominantes procuram forjar dentro do sistema educacional a hierarquia que antes se consolidava através da exclusão ao sistema educacional.

A análise da realidade educacional desvela a capacidade de adaptação, principalmente, da escola particular frente a uma gestão educacional que nem sempre a beneficiava ${ }^{19}$, mas que abria possibilidades quanto a sua participação no interior da hierarquia educacional demandada. Isso porque os empresários que vendem a educação como uma mercadoria não são motivados por sua qualidade, mas pela potencialidade de seus lucros. Desse modo, os empresários de ensino se adaptam às diferentes clientelas, adequando a qualidade de seu ensino à quantidade que seus clientes podem pagar. Essa flexibilidade das instituições particulares contribuiu para a materialização das hierarquias sociais no interior do sistema escolar.

No período em análise, observamos como essa rede se manteve forte em níveis de ensino onde já havia se estabelecido - ainda que tenha reduzido a sua participação proporcional no $2^{\circ}$ grau - e ainda estendeu a sua atuação para outros campos, antes menos ocupados, como o supletivo e o ensino superior. Além disso, na primeira oportunidade conjuntural, participou do processo em que a profissionalização universal foi posta em questão e, pouco tempo depois, seria descaracterizada a partir de uma nova lei, em 1982. (FREITAG, 1986)

Desse modo, além da ingerência sobre a produção legislativa, a burguesia precisou se adaptar à legislação, adaptando-a a seu favor, de modo que as suas contradições se diluíssem na realidade educacional. Ainda que, na maior parte das vezes, essas adequações sejam previsíveis para os agentes da legislação, as lacunas deixadas, que permitem o espaço para adaptação, não são fruto simplesmente de um maquiavelismo, mas também da própria hierarquia de prioridades do pensamento burguês.

\section{Conclusão}

\footnotetext{
${ }^{19} \mathrm{~A}$ despeito de algum prejuízo com o custo da profissionalização, muitas foram as medidas que atendiam as demandas dos empresários, se destacando o salário-educação e a previsão de auxilio técnico e financeiro, pela mesma lei que colocou a profissionalização.
}

TrabalhoNecessario - www.uff.br/trabalhonecessario; Ano 15, №28/2017 
No período que analisamos, quando as tensões entre capital e trabalho se acirraram, a democratização da educação se mostrou, ao mesmo tempo, uma necessidade e um perigo para a reprodução da estrutura de classes. Nesse caso, a expansão deveria ser acompanhada de um controle direto sobre o processo educativo, além de contar com a hierarquização educacional e a mercantilização do ensino como forma de desqualificar determinadas instituições. Essas alternativas, que a realidade possibilitava, resolviam ainda outros problemas relativos às próprias frações burguesas. Isso porque, entre as demandas dos diferentes setores produtivos, também os empresários de ensino disputavam os rumos da educação, tendo em vista os lucros que podem ser obtidos com a sua mercantilização. Se, na teoria, os projetos do IPES e dos CONEPEs eram heterogêneos, na prática, eles se complementavam para a reprodução das desigualdades, materializadas no dualismo educacional.

Em síntese, podemos dizer que a educação sofreu, nesse período, uma inflexão que teria como características principais a orientação tecnicista do sistema educacional e o favorecimento à mercantilização do ensino. Isso materializa as necessidades das frações de classe burguesas, cujos benefícios com a educação são incontáveis, mas também as lutas sociais que marcaram o contexto. Se, por um lado, a complexificação do sistema produtivo gerava um incremento na demanda por mão de obra qualificada, por outro, a vinculação dessa formação com a escola formal foi fruto da mobilização da sociedade em prol da expansão educacional.

\section{Referências Bibliográficas}

BRUNO, Lúcia. Educação e desenvolvimento econômico no Brasil. Revista Brasileira de Educação. v. 16 n. 48, p. 545-562, set-dez. 2011.

CAMPOS, Renata A. O IPES E OS CONEPEs: Conflitos e Consensos em torno dos rumos da política educacional da ditadura empresarial-militar brasileira. 2016. 202f. Dissertação (Mestrado em Educação) - UFF, Niterói.

CARCANHOLO, R. \& Nakatani, P. O Capital Especulativo Parasitário: uma precisão teórica sobre o capital financeiro, característico da globalização, 1999. Disponível em: http://sites.uol.com.br/carcanholo Acesso em: 15 jul. 2014. 
CARDOSO, Miriam Limoeiro. Sobre a teorização do capitalismo dependente em Florestan Fernandes. In: FÁVERO, Osmar (org.). Democracia e educação em Florestan Fernandes. Rio de Janeiro: Eduff/Autores Associados, 2005.

CONEPE. 8., 1964, Salvador. Anais... Salvador, 1964. . 9., 1966, Curitiba. Anais... Curitiba, 1966. . 10., 1967, Fortaleza. Anais... Fortaleza, 1967. . 11., 1969, Rio de Janeiro. Anais... Rio de Janeiro, 1969. . 12., 1971, Recife. Anais... Recife, 1971.

CUNHA, Luís Antônio. Política Educacional no Brasil: a profissionalização no ensino médio. Rio de Janeiro: Eldorado, 1973.

Educação e Desenvolvimento Social no Brasil. Rio de Janeiro: Francisco Alves, 1977. A Universidade Reformanda. Rio de Janeiro: Francisco

Alves, 1988.

DREIFUSS, René Armand. 1964: a conquista do Estado. Ação Política, Poder e Golpe de Classe. Petrópolis: Vozes, 1981.

FERNANDES, Florestan. Os dilemas da reforma universitária consentida. In: Universidade Brasileira: reforma ou revolução? São Paulo: Alfa-Omega, 1975. A revolução burguesa no Brasil. São Paulo: Globo, 2005.

FREITAG, Bárbara. Escola, Estado e Sociedade. São Paulo: Editora Moraes, 1986.

FRIGOTTO, G. A produtividade da escola improdutiva. São Paulo: Cortez Editora e Autores Associados, 1984.

GERMANO, José Willington. Estado militar e educação no Brasil. São Paulo: Cortez editora, 1993.

GRAMSCI, Antonio. Cadernos do Cárcere, volume 3: Maquiavel. Notas sobre o Estado e a Política. 6 ed. Rio de Janeiro: Civilização Brasileira, 2014.

IPES. A educação que nos convém. Rio de Janeiro: Apec, 1969.

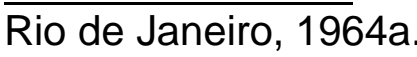

. Simpósio sobre a Reforma da Educação. Documento Básico. 
. Simpósio sobre a Reforma da Educação. Delineamento Geral de um Plano de Educação para a Democracia no Brasil. Rio de Janeiro, 1964b.

LEHER, Roberto. Florestan Fernandes e a Universidade no capitalismo dependente. In: FÁVERO, Osmar (org.). Democracia e educação em Florestan Fernandes. Rio de Janeiro: Eduff/Autores Associados, 2005.

A universidade reformanda: atualidade para pensar tendências da educação superior 25 anos após sua publicação. Revista Contemporânea de Educação, vol. 8, n. 16, agosto/dezembro de 2013.

LIRA, Alexandre Tavares Nascimento. A legislação de educação no Brasil durante o regime militar (1964-1985): um espaço de disputas. 2010. 367f. Tese (Doutorado em Educação) - UFF, Niterói.

MOTTA, Vânia C. \& MAGALHÃES, Ligia K. Tecnologia Social: massificação periférico-dependente revestida pelo discurso de universalização da educação básica brasileira. In: ANDRADE, Juarez (Org.) O Estado Brasileiro e a Educação Básica: os limites da universalização. Juiz de Fora: FABEB: Editora UFJF (no prelo).

RODRIGUES, José. Os empresários e a educação superior. Campinas: Autores Associados, 2007.

ROMANELLI, Otaíza de O. História da Educação no Brasil. Petrópolis: Vozes, 1982.

SAVIANI, Dermeval. O Legado Educacional do Regime Militar. Caderno Cedes. Campinas, v. 28, n. 76, p. 302, set-dez. 2008.

Autores Associados, 2010.

História das idéias pedagógicas no Brasil. 3aㅡ ed. Campinas,

SHULTZ, Theodore W. O Capital Humano: investimentos em educação e pesquisa. Rio de Janeiro: Zahar, 1973.

SILVEIRA, Zuleide S. Contradições entre capital e trabalho: concepções de educação tecnológica na reforma do ensino médio e técnico. São Paulo: Paco Editorial, 2010

Concepções de educação tecnológica na reforma da educação superior: finalidades, continuidades, e rupturas - estudo comparado Brasil e Portugal (1995-2010). 2011. 445f. Tese (Doutorado em Educação) - UFF, Niterói.

Recebido em: 2 de novembro de 2016. Aprovado em: 22 de novembro de 2017.

Publicado em: 31 de janeiro de 2018. TrabalhoNecessario - www.uff.br/trabalhonecessario; Ano 15, №28/2017 